\title{
Sistema radicular de plantas cítricas e atributos físicos do solo em um Latossolo argiloso submetido à escarificação
}

\author{
Root system of citrus plants and soil physical properties of a clayey \\ oxisol submitted to scarification
Ivan Bordin ${ }^{1}$ Carmen Silvia Vieira Janeiro Neves ${ }^{2}$ Fernando Tsuyoshi Aida $^{3}$
Waltoyr Romero de Souza ${ }^{3}$ Antonio Carlos Davoglio Junior ${ }^{3}$
Thiago Luiz Ragugnetti Furlaneto ${ }^{3}$ João Tavares Filho $^{4}$

\section{RESUMO}

\begin{abstract}
O trabalho teve como objetivo avaliar a influência da escarificação sobre atributos físicos do solo e sobre a distribuição do sistema radicular do limão 'Cravo' (Citrus limonia Osb) sob copa de laranja 'Pêra' (Citrus sinensis $L$. $O s b)$. Foram abertas quatro trincheiras para cada tratamento (entrelinha escarificada e entrelinha não escarificada) avaliando-se distribuição das raizes na linha e entrelinha até a profundidade de 1,0 m pelo Sistema Integrado de Análise de Raízes e Cobertura do Solo (SIARCS 3.0). A porosidade total $e$ a densidade do solo foram avaliadas em três profundidades (0,000-0,125; 0,125-0,250 e 0,25-0,375 m) em três posições: linha, centro da entrelinha e limite da copa na entrelinha. Três anos depois da escarificação não se detectou alteração para a densidade e a porosidade total do solo nas entrelinhas do pomar e a quantidade de raízes, independentemente da profundidade e posição em relação à planta.
\end{abstract}

Palavras-chave: densidade do solo, porosidade, raízes, citros.

\section{ABSTRACT}

The work had as objective to evaluate the influence of the scarification on physical attributes of the soil and on the distribution of the root system of Rangpur lemon budded with the 'Pêra' orange. Four trenches were digged for each treatment (inter-row scarified and inter-row not scarified) The distribution of the roots in the row and inter-row were evaluated down to $1.0 \mathrm{~m}$ depth with the SIARCS 3.0 software (Sistema Integrado de Análise de Raízes e Cobertura do Solo). The total porosity and soil bulk density were evaluated in three depths (0.000-0.125; 0.125-0.250 and 0.25-0.375 m) in three sites: row, inter-row and limit of the tree canopy in the interrow. Three years after scarification there were no differences among treatments for soil total porosity and bulk density on inter-rows and for the amount of roots of all depths and sites.

Key words: bulk density, porosity, roots, citrus.

\section{INTRODUÇÃO}

As plantas cítricas adaptam-se bem a vários tipos de solos desde que tenham boa porosidade, permeabilidade e não existam limitações físicas ao desenvolvimento do seu sistema radicular, o qual tem relação direta com o volume da copa e a produção de frutos (OLIVEIRA, 1991).

Um grave problema encontrado em pomares cítricos refere-se à compactação do solo, que se dá devido ao tráfego excessivo, representado pelo elevado número de operações como adubações, pulverizações e controle de plantas daninhas, que tendem a se agravar na colheita das variedades tardias, que coincide com o

${ }^{1}$ Programa de Pós-graduação em Agronomia, Universidade Estadual de Londrina (UEL), Brasil. E-mail: ivanbordin@uel.br. ${ }^{2}$ Departamento de Agronomia, UEL, CP 6001, 86051-990, Londrina, PR, Brasil. Bolsista em Produtividade do Conselho Nacional de Desenvolvimento Científico e Tecnológico (CNPq). E-mail: csvjneve@uel.br.

${ }^{3}$ Curso de Agronomia, UEL, Londrina, PR, Brasil.

${ }^{4}$ Departamento de Agronomia, UEL, CP 6001, 86051-990, Londrina, PR, Brasil. 
período chuvoso, facilitando a compactação pela passagem das carretas e caminhões (TERSI \& ROSA, 1995). A compactação nos pomares cítricos pode ocorrer por toda área ou em locais determinados, que nem sempre são no centro das ruas, devido a distribuição do peso dos implementos pelos rodados (STOLF, 1987).

Em relação à distribuição das raízes, NEVES et al. (1998/2004) observaram que a distância efetiva do sistema radicular das plantas cítricas, até onde se concentra $80 \%$ do sistema radicular, variou de 1,5 a 3,7m em relação ao tronco das plantas, sendo essa distância influenciada pelo espaçamento, variedade de portaenxerto e manejo do solo utilizado nas entrelinhas. Para a profundidade efetiva do sistema radicular das plantas cítricas, tem-se observado de 0,40 a $0,75 \mathrm{~m}$, sendo esta profundidade influenciada por atributos físicos, químicos e biológicos do solo (NEVES et al., 1998; CINTRA et al., 1999; NEVES et al., 2004).

A subsolagem modifica a estrutura do solo, reduzindo a resistência à penetração radicular, contribuindo na melhoria da circulação de ar, água e nutrientes e aumentando o volume de solo explorado pelas raízes, como foi observado em limão 'Cravo' sob laranja 'Pêra' (RESENDE et al., 2002). Apesar disso, STOLF (1987) relata que a subsolagem é fonte de controvérsias, pois os benefícios advindos das melhorias das propriedades físicas do solo podem ser anulados ou mesmo tornados negativos pelos prejuízos causados ao sistema radicular. A descompactação mecânica, com subsolagem ou escarificação, pode ser realizada na instalação ou no manejo da cultura, porém não há um critério definido em relação à distância mínima das plantas cítricas para passar o implemento sem causar danos ao sistema radicular (CASTRO \& LOMBARDI NETO, 1992). O sucesso da escarificação depende também do tipo de solo e seu nível de compactação e umidade, do tipo de implemento utilizado e da permanência do efeito descompactador da operação nas condições estruturais do solo (CAMARGO, 1983).

Apesar da importância do sistema radicular na absorção de água e nutrientes, a influência de práticas de manejo na melhoria das condições físicas do solo relacionadas ao crescimento das raízes dos citros tem sido pouco estudada. Neste contexto, o trabalho teve como objetivo avaliar a influência da escarificação sobre a distribuição do sistema radicular do limão 'Cravo' sob copa de laranja 'Pêra' e atributos físicos de um Latossolo argiloso.

\section{MATERIAL E MÉTODOS}

O trabalho foi realizado em maio de $2003 \mathrm{em}$ um pomar comercial formado por plantas de laranja
'Pêra' (Citrus sinensis L. Osb.) enxertadas sobre limão 'Cravo' (Citrus limonia Osb.), em um Latossolo Vermelho distroférrico típico de textura argilosa (EMBRAPA, 1999) localizado no município de Rolândia - PR, cujas coordenadas geográficas são $23^{\circ}$ $27^{`} \mathrm{~S}, 51^{\circ} 47^{`} \mathrm{~W}$, com $600 \mathrm{~m}$ de altitude, precipitação média anual de $1610 \mathrm{~mm}$ e temperatura média anual de $21,2^{\circ} \mathrm{C}$. Aárea era cultivada com cana-de-açúcar desde 1975 e, após três anos com cultivo de soja, foi implantado o pomar cítrico em 1993 com o espaçamento de 7,0 x 3,5m. O pomar é adubado seguindo a recomendação do GRUPO PAULISTA DE ADUBAÇÃO E CALAGEM PARA CITROS (1994) e recebe tratamento fitossanitário quando necessário. As plantas daninhas são manejadas com glifozate nas linhas de plantio, enquanto as entrelinhas são roçadas periodicamente.

Foi realizada uma escarificação alternada nas entrelinhas em todo pomar, numa única passagem no centro das mesmas, em maio de 2000, com escarificador de três pontas distanciadas $1,0 \mathrm{~m}$, à profundidade de $0,30 \mathrm{~m}$. Para a avaliação do efeito desta prática foram considerados dois tratamentos: as entrelinhas escarificadas (EE) e não escarificadas (ENE), num delineamento experimental inteiramente casualizado.

Para avaliação do sistema radicular foram abertas quatro trincheiras para cada tratamento, a 0,10m do tronco das árvores, com comprimento de $1,75 \mathrm{~m}$ na linha de plantio, e de 3,5m na entrelinha, com profundidade de $1,0 \mathrm{~m}$. Foi utilizado o método do perfil para avaliação das raízes, que foram expostas com escarificador manual, em forma de rolo, com pregos sem cabeça e coloridas com tinta branca (BÖHM, 1979). Uma moldura de madeira dividida por fios de nylon em quadrículas de $0,25 \times 0,25 \mathrm{~m}$, foi afixada ao perfil e foram obtidas imagens de cada quadrícula com câmera digital. As imagens foram avaliadas pelo Sistema Integrado de Análise de Raízes e Cobertura do Solo - SIARCS 3.0 (CRESTANA et al., 1994). Cada quadrícula foi subdividida em quatro imagens de 0,125 x 0,125m, obtendo-se como variável o comprimento das raízes. As avaliações foram realizadas em relação à distribuição das raízes em profundidade e distância do tronco, juntamente com suas respectivas profundidades e distâncias efetivas, até onde se concentram 80\% do sistema radicular (KLAR, 1991). Os dados foram submetidos à análise de variância e teste Tukey com 5\% de probabilidade de erro.

Para análise do solo, foram coletadas amostras em três profundidades $(0,000-0,125 ; 0,125$ $0,250 ; 0,250-0,375 \mathrm{~m})$, objetivando a determinação da densidade do solo, pelo método do anel volumétrico 
(EMBRAPA, 1997) e porosidade total, através da correlação das densidades do solo com a densidade das partículas (KIEHL, 1979), adotando-se o valor de $2,83 \mathrm{~kg} \mathrm{dm}^{-3}$ como densidade das partículas para o solo estudado (NEVES, 1998). As amostras foram coletadas na linha de plantio, no limite da copa na entrelinha e no centro da entrelinha, onde foi realizada a escarificação. A linha de plantio e o limite da copa na entrelinha foram amostrados com oito repetições enquanto que a entrelinha foi dividida em dois tratamentos (escarificado e não escarificado) constando de quatro repetições. Os dados foram submetidos à análise de variância e teste Tukey a 5\% de probabilidade de erro.

\section{RESULTADOS E DISCUSSÃO}

O crescimento radicular não foi afetado pela escarificação em todos os locais amostrados (Tabela 1). Segundo NEVES et al. (1998), o crescimento radicular pode se dar de uma forma compensatória, com maior ocorrência de raízes em regiões do solo mais propícias ao seu crescimento em relação a locais que apresentam restrições, o que não foi evidenciado neste trabalho, pois não se verificou nenhum tipo de compensação do crescimento radicular em função da escarificação. A falta de respostas entre os tratamentos com e sem escarificação na entrelinha está de acordo com ANDRIOLI et al. (2003), que também não constataram respostas do sistema radicular da tangerina 'Sunki' sob laranja 'Valência' num Latossolo Vermelho de textura média um ano após a subsolagem à profundidade de $0,40 \mathrm{~m}$. Porém RESENDE et al. (2002), ao avaliarem os efeitos da subsolagem a $0,50 \mathrm{~m}$ de profundidade no preparo do solo de um Latossolo Amarelo Coeso, concluíram que a subsolagem modificou a estrutura do solo, reduzindo significativamente a resistência à penetração radicular, contribuindo na melhoria da circulação do ar, água, nutrientes e aumentando o volume de solo explorado pelas raízes de limão 'Cravo' sob três variedades de copa. Segundo estes últimos autores, os solos com horizontes coesos dispõem de proporções de vários tamanhos de areias que juntamente com o pouco de argila e silte existentes, induzem a uma união dessas frações, formando camadas muito duras que limitam o crescimento radicular das plantas cítricas ao volume da cova de plantio, sendo necessário revolver o solo em profundidade na ocasião da instalação do pomar.

Em relação à distribuição de raízes por distância do tronco na entrelinha (Figura 1), nota-se que só foram encontradas diferenças nas distâncias de 0,125-0,250 e 1,125-1,250m com a superioridade da entrelinha escarificada sobre a entrelinha não escarificada, enquanto no restante das distâncias avaliadas não houve diferenças entre os tratamentos. Por outro lado, CARVALHO et al. (1999) encontraram melhorias na distribuição do sistema radicular do limão 'Cravo' sob laranja 'Pêra', na entrelinha, a partir da profundidade de $0,40 \mathrm{~m}$ até $1,0 \mathrm{~m}$ quando associaram subsolagem ao manejo da leguminosa feijão-de-porco.

Na tabela 2, estão os dados referentes à profundidade e distância efetivas do sistema radicular, até onde se concentram $80 \%$ das raízes e ao raio da copa na linha e entrelinha. Não foi constatada diferença para estas variáveis entre os tratamentos. A profundidade efetiva observada na linha e entrelinha variou de 0,55 a $0,65 \mathrm{~m}$, corroborando com os

Tabela 1 - Comprimento de raízes de limão 'Cravo' sob laranja 'Pêra' em diferentes profundidades na linha e entrelinha de plantio dos tratamentos com (EE) e sem (ENE) escarificação. Rolândia-Pr, 2003.

\begin{tabular}{|c|c|c|c|c|c|c|}
\hline \multirow{3}{*}{ Profundidade(m) } & \multicolumn{6}{|c|}{ Comprimento (m) } \\
\hline & \multicolumn{3}{|c|}{ Linha } & \multicolumn{3}{|c|}{ Entrelinha } \\
\hline & $\mathrm{EE}$ & ENE & $\mathrm{CV} \%$ & $\mathrm{EE}$ & ENE & $\mathrm{CV} \%$ \\
\hline $0,000-0,125$ & $2,31 \mathrm{a}^{*}$ & $1,50 \mathrm{a}$ & 47,1 & $2,24 \mathrm{a}$ & $2,34 \mathrm{a}$ & 39,8 \\
\hline $0,125-0,250$ & $1,07 \mathrm{a}$ & $0,97 \mathrm{a}$ & 33,0 & $1,50 \mathrm{a}$ & $1,32 \mathrm{a}$ & 22,0 \\
\hline $0,250-0,375$ & $0,54 \mathrm{a}$ & $0,57 \mathrm{a}$ & 32,5 & $1,02 \mathrm{a}$ & $1,28 \mathrm{a}$ & 22,2 \\
\hline $0,375-0,500$ & $0,48 \mathrm{a}$ & $0,34 \mathrm{a}$ & 28,4 & $0,87 \mathrm{a}$ & $1,10 \mathrm{a}$ & 19,6 \\
\hline $0,500-0,625$ & $0,37 \mathrm{a}$ & $0,19 \mathrm{a}$ & 30,6 & $0,85 \mathrm{a}$ & $1,23 \mathrm{a}$ & 45,3 \\
\hline $0,625-0,700$ & $0,35 \mathrm{a}$ & $0,50 \mathrm{a}$ & 41,7 & $0,69 \mathrm{a}$ & $1,01 \mathrm{a}$ & 42,8 \\
\hline $0,700-0,875$ & $0,32 \mathrm{a}$ & $0,28 \mathrm{a}$ & 21,1 & $0,74 \mathrm{a}$ & $0,69 \mathrm{a}$ & 40,2 \\
\hline $0,875-1,000$ & $0,24 \mathrm{a}$ & $0,52 \mathrm{a}$ & 58,3 & $0,50 \mathrm{a}$ & $0,55 \mathrm{a}$ & 17,8 \\
\hline Total & $5,68 \mathrm{a}$ & $4,66 \mathrm{a}$ & 15,4 & $8,41 \mathrm{a}$ & $9,52 \mathrm{a}$ & 17,7 \\
\hline
\end{tabular}

*Letras iguais na linha não diferem entre si pelo teste de Tukey a 5\% de significância. 


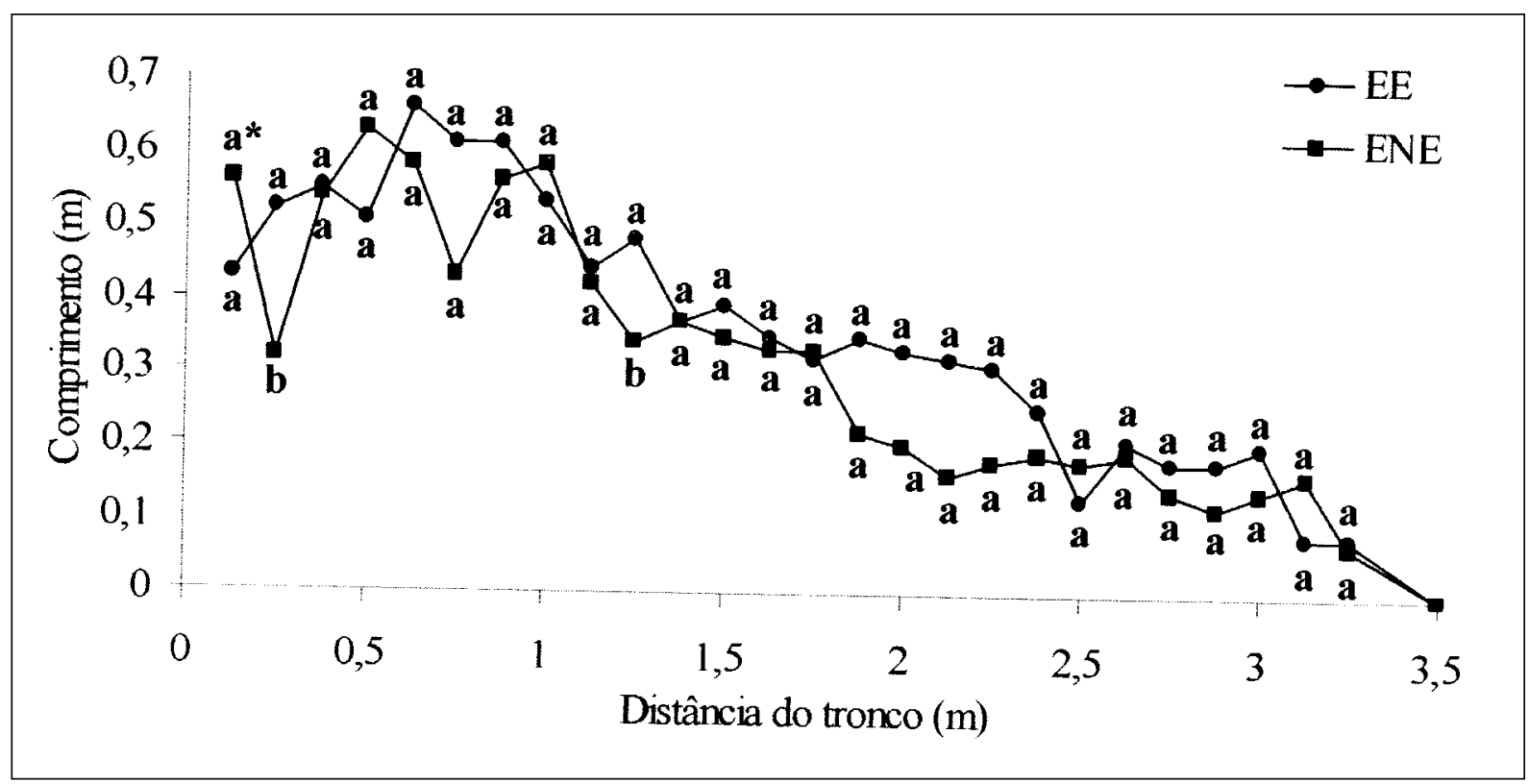

Figura 1 - Comprimento de raízes de limão 'Cravo'sob laranja 'Pêra', por distânciado tronco para entrelinha escarificada (EE) e não escarificada (ENE).Rolândia-PR,2003.

*Letras iguais entre os tratamentos não diferem entre si pelo teste de Tukey a $5 \%$ de significância.

resultados encontrados por NEVES et al. (1998 e 2004) ao trabalharem no mesmo tipo de solo do presente trabalho até a profundidade de $1,0 \mathrm{~m}$. Porém, CINTRA et al. (1999), ao avaliarem o sistema radicular de vários porta-enxertos sob Laranja 'Pêra' até $1,0 \mathrm{~m}$ de profundidade em solo com horizonte coeso, constataram que $90 \%$ das raízes estavam concentradas a $0,4 \mathrm{~m}$ de profundidade, devido ao impedimento físico do horizonte coeso.

Nota-se que, independentemente da escarificação, a distância efetiva do sistema radicular na entrelinha, está distribuída entre 1,96 a 1,98m, estando muito próximo ao raio da copa na entrelinha, que foi de $1,81 \mathrm{~m}$ para o tratamento escarificado e $1,74 \mathrm{~m}$ para o tratamento não escarificado (Tabela 3). Estes resultados reforçam as recomendações de adubação e calagem para plantas com mais de três anos, que recomendam a aplicação de $2 / 3$ destes insumos sob a projeção da copa e 1/3 fora (GRUPO PAULISTA DE ADUBAÇÃO ECALAGEM PARACITROS, 1994).

Para a densidade do solo, na profundidade de 0,125-0,250 m, a entrelinha não escarificada e o limite da copa na entrelinha foram superiores à linha de plantio, que não se diferenciou da entrelinha (Tabela 3). Esta menor densidade do solo na linha de plantio não foi constatada por SANCHES et al. (1999), ao compará-la com a entrelinha de um pomar cítrico num Podzólico Vermelho-Amarelo eutrófico, quando avaliaram as alterações na densidade do solo resultantes da implantação da cultura de citros. Contudo, está de acordo com o trabalho de GOMES et al. (2003), que encontraram densidades menores na linha de plantio em relação ao

Tabela 2 Profundidade efetiva na linha (PEL), profundidade efetiva na entrelinha (PEE), distância efetiva na linha (DEL), distância efetiva na entrelinha (DEE) do sistema radicular e raio da copa na linha (RCL), raio da copa na entrelinha (RCE) de plantas de limão 'Cravo' sob laranja 'Pêra', submetidas (EE) ou não (ENE) à escarificação. Rolândia-Pr, 2003.

\begin{tabular}{lcccccc}
\hline Tratamentos & PEL & PEE & DE L & DEE & RCL \\
\hline & & & & $\mathrm{m}$ & & \\
EE & $0,55 \mathrm{a}^{*}$ & $0,65 \mathrm{a}$ & $0,96 \mathrm{a}$ & $1,98 \mathrm{a}$ & $1,46 \mathrm{a}$ & $1,81 \mathrm{a}$ \\
ENE & $0,65 \mathrm{a}$ & $0,65 \mathrm{a}$ & $0,97 \mathrm{a}$ & $1,96 \mathrm{a}$ & $1,47 \mathrm{a}$ & $1,74 \mathrm{a}$ \\
CV $\%$ & 15,68 & 10,27 & 3,43 & 19,47 & 6,48 & 64 \\
\hline
\end{tabular}

*Letras iguais na linha não diferem entre si pelo teste de Tukey a 5\% de significância.

Ciência Rural, v.35, n.4, jul-ago, 2005. 
Tabela 3 - Densidade do solo e porosidade total nas diferentes profundidades da linha, limite da copa na entrelinha (LCE), entrelinha escarificada (EE) e centro da entrelinha não escarificada (ENE), em pomar de limão 'Cravo' sob laranja 'Pêra'. Rolândia-Pr, 2003.

\begin{tabular}{|c|c|c|c|c|c|}
\hline \multirow{3}{*}{ Profundidade $(\mathrm{m})$} & \multicolumn{4}{|c|}{ Locais de amostragem } & \multirow[b]{3}{*}{$\mathrm{CV} \%$} \\
\hline & \multirow[b]{2}{*}{ Linha } & \multicolumn{3}{|c|}{ Entrelinha } & \\
\hline & & LCE & $\mathrm{EE}$ & ENE & \\
\hline \multicolumn{6}{|c|}{ Densidade do solo $\left(\mathrm{kg} \mathrm{dm}^{-3}\right)$} \\
\hline $0,000-0,125$ & $1,22 \mathrm{a}$ & $1,32 \mathrm{a}$ & $1,28 \mathrm{a}$ & $1,28 \mathrm{a}$ & 8,1 \\
\hline $0,125-0,250$ & $1,18 \mathrm{~b}$ & $1,39 \mathrm{a}$ & $1,30 a b$ & $1,34 \mathrm{a}$ & 7,1 \\
\hline $0,250-0,375$ & $1,18 \mathrm{a}$ & $1,25 \mathrm{a}$ & $1,38 \mathrm{a}$ & $1,25 \mathrm{a}$ & 9,1 \\
\hline \multicolumn{6}{|c|}{ Porosidade total $\left(\mathrm{m}^{3} \mathrm{~m}^{-3}\right)$} \\
\hline $0,000-0,125$ & $0,57 \mathrm{a}$ & $0,53 \mathrm{a}$ & $0,55 \mathrm{a}$ & $0,55 \mathrm{a}$ & 6,8 \\
\hline $0,125-0,250$ & $0,58 \mathrm{a}$ & $0,50 \mathrm{~b}$ & $0,54 a b$ & $0,53 \mathrm{ab}$ & 6,1 \\
\hline $0,250-0,375$ & $0,58 \mathrm{a}$ & $0,56 \mathrm{a}$ & $0,51 \mathrm{a}$ & $0,56 \mathrm{a}$ & 15,4 \\
\hline
\end{tabular}

*Letras iguais na linha não diferem entre si pelo teste de Tukey a 5\% de significância.

limite da copa na entrelinha. Isto se deve ao fato de que, na linha de plantio a ocorrência da passagem de implementos acontece apenas até o preparo do solo para instalação do pomar. Assim, nesse local de amostragem, o solo cuja precipitação média anual de $1.610 \mathrm{~mm}$ concentrada nos meses de setembro a março, período em que ocorre o crescimento vegetativo dos citros, pode ter contribuído para o crescimento das raízes. Segundo MAZZA et al. (1994), o regime hídrico apresenta grande importância para o desenvolvimento do sistema radicular das plantas cítricas, reduzindo os efeitos negativos da compactação do solo. O desenvolvimento radicular das plantas cítricas ocorre por fluxos (BEVINGTON \& CASTLE, 1985) que, quando coincidem com a estação das chuvas, podem explicar o crescimento de raízes no perfil do solo mesmo em condições físicas não ideais.

\section{CONCLUSÕES}

A escarificação não altera a densidade e a porosidade total do solo nas entrelinhas do pomar e a quantidade de raízes, independentemente da profundidade e posição em relação à planta.

\section{AGRADECIMENTOS}

Os autores agradecem a Sra. Jennifer Kaphan, Engenheiro Agrônomo Ademir Manjavak e Cooperativa COROL (Rolândia-Pr) pelas condições proporcionadas para a realização do trabalho.

\section{REFERÊNCIAS}

ANDRIOLI, I. et al. Influência da subsolagem e adubação verde no sistema radicular do citros em um Latossolo Vermelho. In: CONGRESSO BRASILEIRO DE CIÊNCIA DO SOLO, 31., 2003, Ribeirão Preto, SP. Anais... Ribeirão Preto : Sociedade Brasileira de Ciência do Solo, 2003. CD-ROM.
BEVINGTON, K.B.; CASTLE, W.S. Annual root growth pattern of young citrus trees in relation to shoot growth, soil temperature, and soil water content. Journal American Society for Horticultural Science, v.110, n.6, p.840845,1985 .

BÖHM, W. Methods of studying root systems. Berlim: Springer-Verlag, 1979. 188p.

CAMARGO, O.A. Compactação do solo e desenvolvimento de plantas. Campinas : Fundação Cargill, 1983. 44p.

CARVALHO, J.E.B. et al. Manejo de coberturas do solo e sua interferência no desenvolvimento do sistema radicular da laranja 'Pêra'. Revista Brasileira de Fruticultura, v.21, n.2, p.140-145, 1999.

CASTRO, O.M.; LOMBARDI NETO, F. Manejo e conservação do solo em citrus. Laranja, v.13, n.1, p.275305,1992 .

CINTRA, L.D. et al. Distribuição do sistema radicular de portaenxertos de citros em ecossistemas de tabuleiro costeiro. Revista Brasileira de Fruticultura, v.212, n.3, p.313$317,1999$.

CRESTANA, A. et al. Avaliação da distribuição de raízes no solo auxiliada por processamento de imagens. Revista Brasileira de Ciência do Solo, v.18, n.3, p.365-371, 1994.

EMBRAPA - Empresa Brasileira de Pesquisa Agropecuária. Manual de métodos de análise de solos. Rio de Janeiro : Embrapa Solos, 1997. 212p.

EMBRAPA - Empresa Brasileira de Pesquisa Agropecuária. Sistema brasileiro de classificação de solos. Rio de Janeiro : Embrapa Solos, 1999. 412p.

GOMES, E.B. et al. Efeitos da subsolagem e adubação verde nas propriedades físicas do solo cultivado com laranja Valência. In: CONGRESSO BRASILEIRO DE CIÊNCIA DO SOLO, 31., 2003, Ribeirão Preto, SP. Anais... Ribeirão Preto : Sociedade Brasileira de Ciência do Solo, 2003. CD-ROM.

Ciência Rural, v.35, n.4, jul-ago, 2005. 
GRUPO PAULISTA DE ADUBAÇÃO E CALAGEM PARA CITROS - GPACC. Recomendações de adubação e calagem para citros no estado de São Paulo. Laranja, v.15, n. esp, p.1-27, 1994

KIEHL, E.J. Manual de edafologia: relações solo-planta São Paulo : Ceres, 1979. 264p.

KLAR, A.E. Irrigação: freqüência e quantidade de aplicação. São Paulo : Nobel, 1991. 156p.

MAZZA, J.A. et al. Influência da compactação no desenvolvimento do sistema radicular de citros: sugestão de método qualitativo de avaliação e recomendações de manejo. Laranja, v.15, n.2, p.263-275, 1994.

MÜLLER, M.M.L. et al. Influência da compactação do solo em subsuperfície sobre o crescimento aéreo e radicular de plantas de adubação verde de inverno. Revista Brasileira de Ciência do Solo, v.25, n.3, p.531-538, 2001.

NEVES, C.S.V.J. Influência de sistemas de manejo em características de tangerina 'Poncã' sobre limão 'Cravo' e de um Latossolo Roxo. 1998. 158f. Tese (Doutorado em Solos e Nutrição de Plantas) - Curso de Pósgraduação em Agronomia, Escola Superior de Agricultura Luiz de Queiroz.

NEVES, C.S.V.J. et al. Efeito do manejo do solo no sistema radicular de tangerineira 'Poncã' enxertada sobre limoeiro
'Cravo' em Latossolo Roxo. Revista Brasileira de Fruticultura, v.20, n.2, p.246-253, 1998.

NEVES, C.S.V.J. et al. Root distribution of rootstocks for 'Tahiti' lime. Scientia Agricola, v.61, n.1, p.94-99, 2004.

OLIVEIRA, J.B. Solos para citros. In: RODRIGUEZ, O. et al. Citricultura brasileira. Campinas : Fundação Cargill, 1991. p. 196-227.

RESENDE, O.J. et al. Citricultura nos solos dos tabuleiros costeiros: análise e sugestões. Salvador : SEAGRI/SPA, 2002. V.3, 97p

SANCHES, A.C. et al. Impacto do cultivo de citros em propriedades químicas, densidade do solo e atividade microbiana de um Podzólico Vermelho-Amarelo. Revista Brasileira de Ciência do solo, v.23, n.1, p.91-99, 1999.

SILVA, H.R.; ROSOLEM, C.A. Crescimento radicular de espécies utilizadas como cobertura decorrente da compactação do solo. Revista Brasileira de Ciência do Solo, v.25, n.2, p.253-260, 2001

STOLF, R. A compactação do solo e perspectivas da subsolagem em citros. Laranja, v.8, n.2, p.283-308, 1987.

TERSI, F.E.A.; ROSA, S.M. A subsolagem no manejo de solo para os pomares de citros. Laranja, v.16, n.2, p.289-298, 1995. 